\title{
TESTE DE CONDUTIVIDADE ELÉTRICA INDIVIDUAL NA AVALIAÇÃO DA QUALIDADE FISIOLÓGICA DE SEMENTES DE CAFÉ (Coffea arabica L.) ${ }^{1}$
}

\author{
Individual electrical conductivity test for evaluation of the physiological quality of \\ coffee seeds (Coffea arabica L.)
}

\author{
Paula de Souza Cabral Costa ${ }^{2}$, Maria Laene Moreira de Carvalho ${ }^{3}$
}

\begin{abstract}
RESUMO
O teste de condutividade elétrica é usado para medir os exsudatos das sementes, que certamente refletem a integridade do sistema de membranas. O teste é rápido e de operação simples, mas a metodologia necessita ser testada para cada espécie individualmente para obter uma melhor precisão e exatidão dos resultados. Este trabalho foi conduzido visando determinar o ponto de partição na realização do teste de condutividade elétrica em sementes de café. Dez lotes de sementes de Coffea arabica sem pergaminho, cultivar Acaiá foram usados nesse estudo. Para a avaliação do ponto de partição as sementes foram embebidas por 96 horas e submetidas ao teste de germinação, correlacionando os valores de condutividade observados com os valores obtidos no teste de germinação. $\mathrm{O}$ ponto de partição é de $120,5 \mu \mathrm{S} . \mathrm{cm}^{-1}$, considerando $70 \%$ de germinação.
\end{abstract}

Termos para indexação: Condutividade elétrica, café, qualidade.

\begin{abstract}
The conductivity test is used to measure the leaches from the seeds, which certaintily reflect the membrane system integrity. The test is rapid and it is of simple operation, but the methodology needs to be tested for each individual species in order to reach a better precision and accuracy. This work was conducted to determinate the partition point for the realization of electrical conductivity test in coffee seeds. Ten seed lots of Coffea arabica, cultivar Acaiá, without parchment, were used in this study. For the evaluation of the partition point, seeds were imbibed for 96 hours and submitted to the germination test, with the correlation between the conductivity values and those obtained in the germination test being evaluated. The partition point is $120,5 \mu \mathrm{S}_{\mathrm{cm}} \mathrm{cm}^{-1}$, considering $70 \%$ of germination.
\end{abstract}

Index terms: Electrical conductivity, coffee, quality.

(Recebido para publicação em 14 de janeiro de 2004 e aprovado em 5 de novembro de 2004)

\section{INTRODUÇÃO}

O café é uma das culturas de maior importância econômica e social para o Brasil. Nos últimos anos, a redução da cota da exportação do produto provocou a necessidade de maior qualidade e redução de custos, para atender a demanda de consumidores cada vez mais exigentes.

Dentre todos os setores da cafeicultura o setor sementeiro se destaca, pois da semente depende a qualidade das mudas e o estabelecimento de lavouras com potencial produtivo.

A qualidade de sementes varia com as condições de produção, e o desenvolvimento de métodos de avaliação da qualidade dessas sementes permite detectar com eficiência e rapidez as variações entre lotes.

$\mathrm{O}$ método tradicionalmente usado para avaliar a qualidade fisiológica de sementes se baseia na realização do teste de germinação, que para sementes de café demanda no mínimo 30 dias. $\mathrm{O}$ desenvolvimento de testes mais rápidos para avaliação da viabilidade das sementes pode agilizar o processo produtivo e auxiliar na decisão dos destinos dos lotes de sementes de café.

Um dos métodos mais rápidos e eficientes utilizado para avaliação da qualidade de sementes é o teste de condutividade elétrica (ANDRADE et al., 1995). Esse teste pode avaliar a qualidade do lote ao analisar cada semente em particular - Teste de Condutividade Individual - ou analisar uma amostra por vez e fornecer como resultado uma média de condutividade da solução em que estão os lixiviados das sementes que compõem a amostra - Teste de Condutividade em Massa ("Bulk Conductivity"). O princípio básico dessa técnica é a medição da quantidade de eletrólitos liberados pela semente na água de embebição. Essa quantidade é diretamente proporcional ao grau de desorganização da membrana plasmática e de sua permeabilidade (KRZYZANOWSKI et al., 1999; VIEIRA, 1994).

Apesar do teste de condutividade elétrica ter destaque como um dos testes mais rápidos e promissores na avaliação da qualidade de sementes de diversas

${ }^{1}$ Dissertação de Mestrado.

'Engenheira Agronôma, Mestre em Fitotecnia - Universidade Federal de Lavras/UFLA - Cx. P. 3037 - 37.200-000 - Lavras, MG - Brasil.

${ }^{3}$ Engenheira Agronôma, PhD, Professora da Universidade Federal de Lavras/UFLA - Cx. P. 3037 - 37.200-000 - Lavras, MG - mlaenemc@ufla.br 
espécies, não existem relatos de sua utilização na avaliação da qualidade de sementes de cafeeiro.

Conduziu-se este trabalho com o objetivo de verificar a possibilidade de avaliação da qualidade fisiológica das sementes de diferentes lotes de café pelo teste de condutividade elétrica individual, e determinar os pontos de partição para sementes de café com e sem o pergaminho.

\section{MATERIAL E MÉTODOS}

O trabalho foi realizado no Laboratório de Análise de Sementes do Departamento de Agricultura da Universidade Federal de Lavras (UFLA), em Lavras-MG. Foram utilizados 10 lotes de sementes de café da cultivar Acaiá, provenientes de diferentes produtores do sul de Minas Gerais, sendo 5 lotes da safra 2001 (numerados de 1 a 5) e 5 lotes da safra 2002 (6 a 10).

\section{Teste de Condutividade Elétrica Individual}

Foi realizado utilizando-se 2 repetições de 50 sementes por lote. As sementes foram embebidas por 96 horas, e a leitura da condutividade foi realizada pelo Analisador Automático de Sementes SAD-9000-S, que forneceu os valores de condutividade elétrica de cada semente e o valor do lote em $\mu \mathrm{S} / \mathrm{cm}$.

Nesse experimento, o valor da condutividade elétrica dos lixiviados de cada semente foi devidamente identificado por numeração.

\section{Teste de Germinação (TG)}

Imediatamente após a leitura da condutividade elétrica de cada semente da amostra, essas mesmas sementes foram submetidas ao Teste de Germinação (BRASIL, 1992). De cada célula da bandeja onde ocorreu a lixiviação foi retirada a semente, e na mesma ordem em que se encontrava na bandeja foi semeada no papel de germinação. As 50 sementes de cada lote retiradas da bandeja após a leitura da condutividade foram semeadas em duas subamostras de 25 sementes por rolo de papel. As avaliações foram feitas no $15^{\circ}$ e $30^{\circ}$ dia após a semeadura.

\section{RESULTADOS E DISCUSSÃO}

Os resultados da análise de "Box-plot" permitiram classificar os lotes 2, 3 e 4 como os de qualidade inferior, e os lotes 6, 7, 8, 10 como os de melhor qualidade (Figura 1).

Imediatamente após a leitura, o valor de condutividade elétrica de cada semente foi identificado, e as mesmas sementes foram submetidas ao teste de germinação. Após leitura do teste de germinação, cada semente foi classificada de acordo com o tipo de estrutura a que deu origem: Plântula Normal, Plântula Anormal ou Semente Morta.

Sementes que originaram plântulas normais possuem valores de condutividade elétrica inferiores e pequena variabilidade. A classe de sementes mortas, por sua vez, apresentou uma alta variabilidade e valores de condutividade elétrica bastante altos (Figura 2).

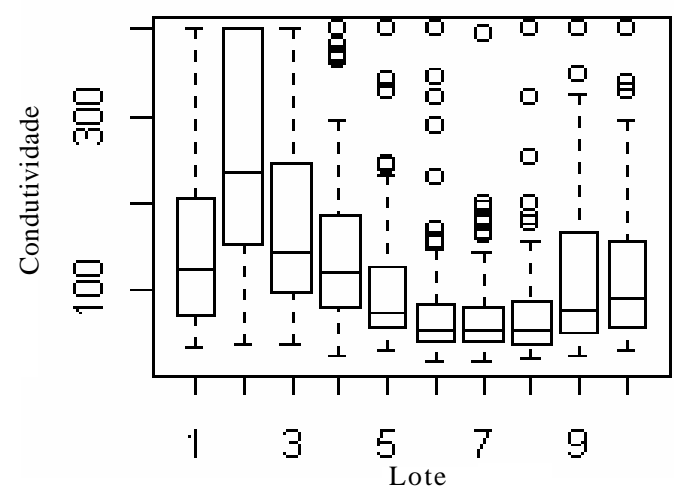

FIGURA 1 - Análise de box-pıtot pàra os resultados médios de condutividade elétrica de individual $\left(\mu \mathrm{S} . \mathrm{cm}^{-1}\right)$ de cada lote para sementes sem o pergaminho. UFLA, Lavras-MG, 2003.

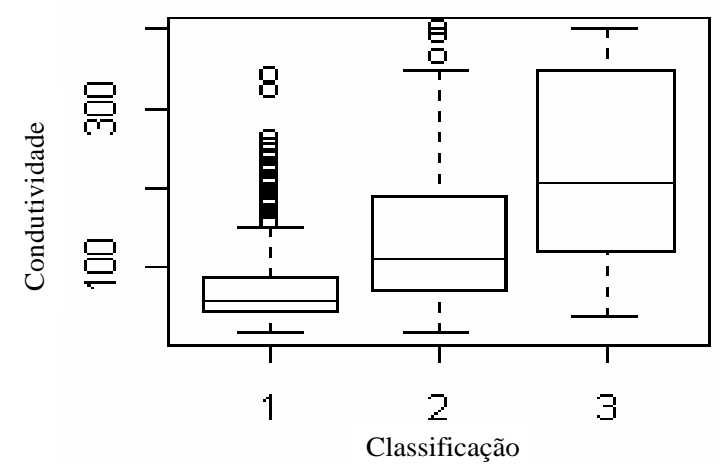

FIGURA 2 - Análise de box-plot para condutividade elétrica individual $(\mu \mathrm{S} / \mathrm{cm})$ para Plântula Normal (1), Anormal (2) e Semente Morta (3), para todos os lotes. UFLA, Lavras-MG, 2003.

A alta variabilidade da classe de sementes mortas é atribuída à presença de muitas sementes que, apesar de mortas, exibiram valores de condutividade muito baixos e àquelas sementes com valores de condutividade muito alto, como era de se esperar. A grande maioria das sementes mortas que exibiram valores de condutividade baixos encontrava-se infeccionadas por fungos, e uma minoria apresentava apenas o embrião deteriorado. 
Segundo Mantovaneli (2001), quando a deterioração dos tecidos é vista externamente à semente, significa que o processo já está num estádio muito avançado. Isso ocorre porque os fungos de campo e de armazenamento podem promover uma deterioração quase total nas sementes, e cascas e tegumentos são deteriorados bem no final do processo. Sementes com baixas condutividades e que originaram plântulas anormais também foram encontradas, provavelmente devido à infecção causada pelos fungos.

Sementes que apresentaram condutividade alta também originaram plântulas normais. Isso ocorreu principalmente em lotes da última safra, ou seja, os de maior qualidade fisiológica, e pode ter sido atribuído à presença de danos mecânicos na semente, que não afetaram o embrião. Deve-se lembrar que a retirada do pergaminho deve ser feita manualmente, pois vários autores alertam que a retirada mecânica causa danos mecânicos à semente, e por muitas vezes, danos que afetaram o embrião.

Os intervalos de valores de condutividade foram menores em se tratando de sementes de alta qualidade fisiológica. Lotes mais vigorosos agruparam valores num intervalo menor, assim como as plântulas normais para todos os lotes, e para a segunda safra.

A ocorrência de grande variabilidade para baixa qualidade fisiológica é confirmada pelo grande intervalo de valores da safra 1 . Na safra 2, observa-se um número grande de valores discrepantes (Figura 3).

De acordo com o interesse do experimento, a resposta pôde ser dada em uma escala discreta, como uma resposta binária caracterizando sucesso ou fracasso. Pode-se considerar a semente comercializável ou não, em virtude da resposta ser binária. Aplicaram-se modelos

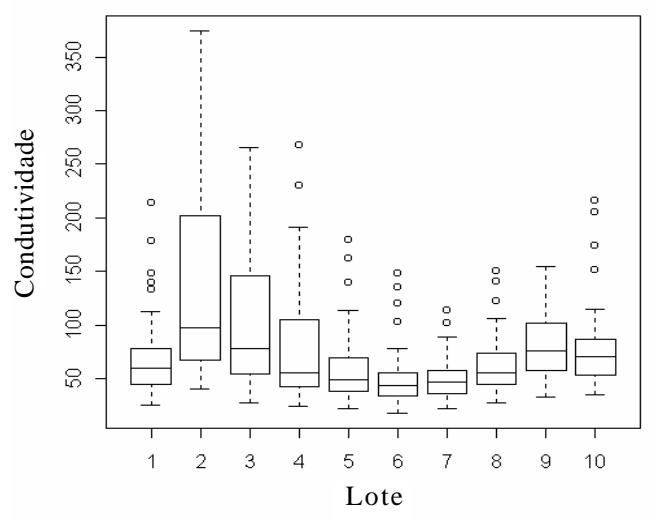

FIGURA 3 - Análise de Box-plot para condutividade elétrica individual $(\mu \mathrm{S} / \mathrm{cm})$ nos 10 lotes de sementes de café com e sem pergaminho. UFLA, Lavras-MG, 2003. generalizados, considerando a variável resposta como distribuição de Bernoulli. A classificação em plântula anormal ou semente morta, considerando apenas o tempo e a condutividade é impossível, pois o modelo indicou a presença de superdispersão, não permitindo estabelecer um índice de classificação.

Com base nos padrões de comercialização de sementes de café - $70 \%$ de germinação -, foi elaborada a expressão da probabilidade da semente ser comercializável ou não, de acordo com sua condutividade elétrica avaliada após 96 h de embebição, e de acordo com a safra ou tempo de armazenamento. $\mathrm{O}$ modelo logístico generalizado para resposta binária de probabilidade neste experimento é dado por:

$$
P(\text { Comercial })=e^{\eta / 1}+e^{\eta},
$$

em que:

$$
\begin{aligned}
& \eta=0,780352-1,016091 \text { Cond. }(\text { Safra } 1) \\
& \eta=2,787866-0,016091 \text { Cond. }(\text { Safra } 2)
\end{aligned}
$$

A Tabela 1 apresenta um paralelo entre os testes convencionais de germinação e tetrazólio com os resultados da condutividade elétrica com $96 \mathrm{~h}$ de embebição proposto pela regressão logística. Observa-se que a separação entre lotes comercializáveis e não comercializáveis, para o teste de condutividade elétrica é semelhante aos testes convencionais. O teste de condutividade elétrica, pelo modelo logístico aplicado, utilizando-se uma probabilidade de comercialização de $70 \%$, como nos testes convencionais, aceita que lotes da safra de 2002 que possuem até $120,5 \mu \mathrm{S} / \mathrm{cm}$ de condutividade, no geral, podem ser comercializados.

Os lotes da safra 2 foram classificados pela numeração binária (1) como comercializáveis, e a menor probabilidade de comercialização entre eles foi para o lote 9 , com $72,56 \%$. Os lotes da safra 1 , com exceção para o lote 5, foram classificados como não comercializáveis (0). O lote 5 foi classificado como comercializável, mas com uma probabilidade baixíssima de $32,26 \%$, que se aproxima muito mais dos lotes não comercializáveis. Isso provavelmente foi reflexo da alta germinação do lote, que apesar de alta, não se correlaciona com o valor de condutividade elétrica alto. Lotes que apresentaram valores de germinação inferiores ao lote 5 mantiveram a condutividade elétrica num mesmo padrão, como no lote 8 , ou até mesmo como no

Ciênc. agrotec., Lavras, v. 30, n. 1, p. 92-96, jan./fev., 2006 
lote 8 , ou até mesmo inferiores, como nos lotes 6 e 7 . A correlação obtida pelos testes convencionais e o teste de condutividade elétrica individual permitiu a obtenção da probabilidade de cada lote ser comercializável ou não. $\mathrm{O}$ vigor avaliado pelo teste de condutividade elétrica foi correlacionado ao perfil exibido pelas sementes de cada lote após o teste de germinação (semente morta, plântula normal ou plântula anormal). Isso possibilitou também acompanhar a velocidade da evolução do processo de deterioração de cada semente individualmente e de cada lote, já que, segundo Delouche (1975), a deterioração da semente começa pela perda da permeabilidade seletiva das membranas celulares e termina com a perda do poder germinativo. Portanto, para a classificação das sementes comercializáveis ou não, foram analisados os processos inicial e final de deterioração e sua evolução. A possibilidade de comercializar o lote foi calculada em virtude dessa evolução, e principalmente do final do processo deteriorativo, constatado pela perda do poder germinativo ou pela morte da semente. As curvas de probabilidades comerciais (Figura 4) para as safras 1 e 2 ilustram a maior probabilidade de se obter sementes comercializáveis para cada valor de condutividade elétrica. Para uma germinação de $70 \%$ num lote de sementes de café da safra 2, o valor de condutividade é de aproximadamente $120,5 \mu \mathrm{S} . \mathrm{cm}^{-1}$.

TABELA 1 - Probabilidade de comercialização de cada lote de sementes de café em relação aos padrões mínimos oficiais exigidos para os testes convencionais de germinação e tetrazólio, e em relação ao teste de condutividade elétrica individual com 96 horas de embebição. Lavras-MG, 2003.

\begin{tabular}{cccccc}
\hline \multirow{2}{*}{ Lote } & \multicolumn{2}{c}{ Testes Convencionais } & \multicolumn{3}{c}{ Teste de Condutividade Elétrica } \\
\cline { 2 - 6 } & Tetrazólio & Germin. & $\begin{array}{c}\text { Condutividade } \\
\text { Elétrica (96h) }\end{array}$ & $\begin{array}{c}\text { Probab. } \\
\text { Comercial. }\end{array}$ & $\begin{array}{c}\text { Classificação } \\
\text { (Safra 2) }\end{array}$ \\
\cline { 2 - 6 } 1 & 47 & 47 & 115,13 & 25,54 & 0 \\
2 & 3,5 & 11 & 251,71 & 3,67 & 0 \\
3 & 39 & 34,5 & 182,375 & 10,41 & 0 \\
4 & 32 & 20 & 149,675 & 16,44 & 0 \\
5 & 71,5 & 89,4 & 94,725 & 32,26 & 1 \\
6 & 93,5 & 81,79 & 73,175 & 83,37 & 1 \\
7 & 89 & 87,5 & 73,53 & 83,29 & 1 \\
8 & 80,5 & 61,5 & 93,32 & 78,38 & 1 \\
9 & 80,5 & 66 & 11 & 72,56 & 1 \\
10 & 85 & 86,35 & 112,685 & 72,64 & 1 \\
\hline
\end{tabular}




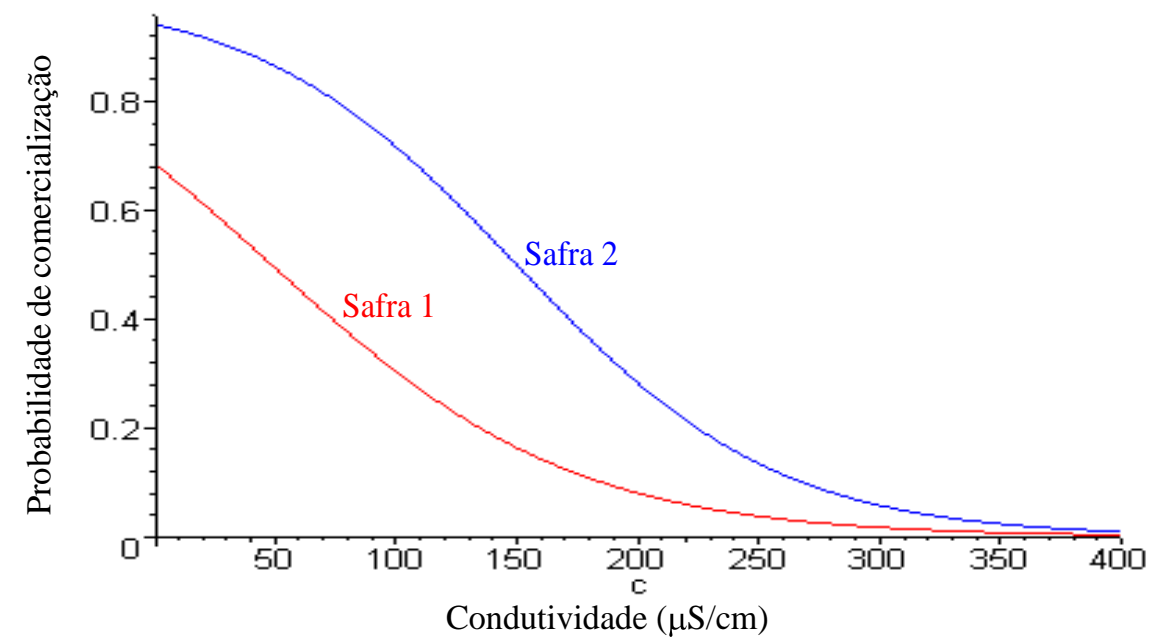

FIGURA 4 - Curvas de probabilidades comerciais para sementes de café das safras de 2001 (1) e de 2002 (2). Lavras-MG, 2003.

\section{CONCLUSÕES}

Os testes de condutividade elétrica individual mostraram-se eficientes na separação de lotes de sementes de café em diferentes níveis de qualidade fisiológica. O ponto de partição para o teste de condutividade elétrica individual, levando em consideração uma germinação de $70 \%$ foi de aproximadamente $120,5 \mathrm{~m} \mu \mathrm{S} / \mathrm{cm}$, para lotes de sementes recém-colhidos.

\section{REFERÊNCIAS BIBLIOGRÁFICAS}

ANDRADE, R. N. B.; SANTOS, D. S. B.; SANTOS FILHO, B. G.; MELLO, V. D. C. Correlação entre testes de vigor em sementes de cenoura armazenadas por diferentes períodos. Pesquisa Agropecuária Gaúcha, Porto Alegre, v. 1, n. 2, p. 153-162, 1995.
BRASIL. Ministério da Agricultura. Regras para análise de sementes. Brasília, DF: SNDA, 1992. 365 p.

DELOUCHE, J. C. Pesquisa em sementes no Brasil. Brasília, DF: Ministério da Agricultura, 1975. 69 p.

KRYZANOWSKI, F. C.; VIEIRA, R. D.; FRANÇA NETO, J. $B$. Vigor de sementes: conceitos e testes. Londrina: ABRATES, 1999. 218 p.

MANTOVANELI, M. C. H. Interferência de alguns fungos no teste de tetrazólio e de danos mecânicos, tratamento fungicida e do armazenamento na qualidade de sementes de milho (Zea mays L.). Lavras: UFLA, 2001.

VIEIRA, R. D. Teste de condutividade elétrica. In: VIEIRA, R. D.; CARVALHO, N. M. (Eds.). Testes de vigor em sementes. Jaboticabal: FUNEP, 1994. p. 103-132. 